\title{
TORNAR-SE FILHO: A PERSPECTIVA DA CRIANÇA NO CONTEXTO DA ADOÇÃO TARDIA
}

\author{
BECOMING A CHILD: THE CHILD'S PERSPECTIVE IN THE LATE ADOPTION CONTEXT \\ CONVERTIRSE EN UN HIJO: LA PERSPECTIVA DEL NIÑO EN EL CONTEXTO DE LA ADOPCIÓN \\ TARDÍA
}

\author{
Ivy Campista Campanha-Araujo* \\ Célia Regina Rangel Nascimento ${ }^{* *}$ \\ Claudia Broetto Rossetti ${ }^{* * *}$
}

\begin{abstract}
RESUMO
Apesar da importância da reciprocidade na construção da vinculação entre pais e filhos, a adoção tardia ainda é realizada no Brasil privilegiando apenas o discurso do adulto, de forma que os sentimentos e o desejo da criança geralmente não são levados em consideração num processo adotivo. Desse modo, o trabalho aqui apresentado teve como objetivo conhecer a visão da criança sobre o processo de tornar-se filho, filha de seus novos pais, num contexto de adoção tardia. Como procedimentos de coleta de dados, foram realizadas entrevistas semiestruturadas, elaboração do genograma e construção do livro biográfico. Com as intervençōes realizadas, pôdese concluir que a criança expressava com silenciamentos conteúdos que a remetiam a aspectos anteriores à chegada à família adotante, demonstrando não querer falar da vivência anterior à adoção, contudo evidenciou, por meio de relatos e desenhos, a construção do vínculo com a família adotiva e o sentir-se integrada ao novo ambiente familiar.
\end{abstract}

Palavras-chave: Adoção tardia. Família adotiva. Perspectiva da criança. Vinculação.

\begin{abstract}
Despite the importance of reciprocity in the construction of the bond between parents and children, late adoption is still performed in Brazil favoring only the adult's discourse, in such a way that the child's feeling and desire are usually not taken into consideration in an adoption process. Thus, the study presented here aims to know the child's perspective in the process
\end{abstract}

\footnotetext{
Texto recebido em 12 de junho de 2016 e aprovado para publicação em 25 de setembro de 2018.

*Doutoranda no Programa de Pós-Graduação em Psicologia da Universidade Federal do Espírito Santo (UFES). E-mail: ivycampanha@gmail.com.

"* Professora doutora no Departamento de Psicologia Social e do Desenvolvimento e no Programa de Pós-Graduação em Psicologia da UFES. E-mail: celiarrn@gmail.com.

*** Professora doutora no Departamento de Psicologia Social e do Desenvolvimento e no Programa de Pós-Graduação em Psicologia da UFES. E-mail: cbroetto.ufes@gmail.com.
} 
of becoming a son/daughter to new parents, in a late adoption context. Our procedures to collect data included semi-structured interviews, development of a genogram and a biographical book. The interventions carried out made it possible to conclude that through silence the child expressed contents that reminded him/her of aspects previous to the arrival at the adoptive family, showing to be unwilling to talk about the experience before the adoption, however made it evident, through reports and drawings, the construction of the bond with the adoptive family and the feeling of being integrated into the new family environment.

Keywords: Late adoption. Adoptive family. Child's perspective. Bond.

\section{RESUMEN}

A pesar de la importancia de la reciprocidad en la construcción de la relación entre padres e hijos, la adopción tardía sigue ocurriendo en Brasil privilegiando el discurso de los adultos, de forma que los sentimientos y los deseos del niño no suelen tenerse en cuenta en un proceso adoptivo. Por lo tanto, el trabajo que aquí se presenta tiene como objetivo conocer la perspectiva del niño en el proceso de convertirse en hijo/hija de sus nuevos padres, en un contexto de adopción tardía. Entrevistas semiestructuradas, construcción del genograma y del libro-biográfico se realizaron como instrumentos de investigación. Se concluyó que, aunque el niño ha expresado con el silencio contenidos que se refieren a los aspectos anteriores a la llegada a la familia adoptiva, demostrando no querer hablar de experiencias previas a la adopción, él demostró, por medio de relatos y dibujos, sentirse integrado $\mathrm{y}$ vinculado al nuevo entorno familiar.

Palabras clave: Adopción tardía. Segunda familia. La perspectiva del niño. Vinculación.

\section{INTRODUÇÃO}

$\mathrm{H}$

istoricamente, quando compete ao sistema de Justiça deferir ou indeferir decisões que selam o destino das crianças, deliberações são realizadas sem levar em consideração o relato destas sobre suas vivências, suas vinculações ou rupturas com a realidade que as cerca. No entanto a literatura aponta e insiste que, também na infância, a pessoa/criança é ativa na construção de sua relação com o contexto bem como com as pessoas e símbolos que fazem parte de sua vida (Bronfenbrenner \& Morris, 2006; Corsaro, 2009). Congruente com esse ponto de vista, este estudo tomou como ponto de partida um posicionamento teórico e metodológico que entende a criança como um ator social que influencia a interação, muitas vezes assumindo um papel de protagonista no relacionamento 
com suas figuras parentais e demais figuras que permeiam seu mundo socioafetivo (Bronfenbrenner \& Morris, 2006).

Pesquisadores têm expressado um amplo interesse em compreender como crianças que vivenciaram a adoção podem se engajar no novo microssistema (Misca \& Smith, 2014; Schweiger \& O’Brien, 2005). Todavia, embora existam inúmeras publicações que articulam pesquisas sobre a adoção a uma lente teórica fundamentada no saber psicológico, são escassos estudos específicos sobre a perspectiva da criança a respeito do processo adotivo (Guimarães, 2010).

A revisão da literatura realizada destaca a realização de alguns estudos sobre adoção que consideraram não só a narrativa dos pais, mas também de seus filhos no que diz respeito à vivência do processo adotivo (Moraes \& Faleiros, 2015; Rossetti-Ferreira, 2010; Vargas, 1998). O estudo de Guimarães (2010), não obstante, configura-se como a única pesquisa, encontrada no contexto brasileiro, que elegeu crianças como participantes centrais em uma pesquisa sobre adoção tardia. Nesta, a autora, em seis encontros com cada criança, coletou seus dados por instrumentos lúdicos e verbais, atribuindo relevo às questôes relacionadas à percepção da criança sobre o processo adotivo. Em sua conclusão, destacou aspectos relacionados à falta de espaço para que as crianças conversassem sobre o processo adotivo, tanto no abrigo quanto na nova família, e o quanto isso provocou ansiedade e sentimentos conflitantes nas crianças, mostrando, assim, a importância de dar voz à criança. Particularmente na adoção tardia, que é definida como sendo a adoção de crianças com idade superior a 2 anos (Silva, 2010; Vargas, 1998), é importante conhecer, respeitar e acolher as transiçóes pelas quais a criança passou até chegar à nova família (Guimarães, 2010).

De acordo com o Departamento de Pesquisa Judiciária (DPJ), ligado ao Conselho Nacional de Justiça (CNJ), um levantamento realizado em 2016 concluiu que a idade avançada é o maior empecilho para a adoção, superando variáveis significativas como doenças e cor da pele (Fariello, 2016). Verifica-se que a maior parte dos postulantes à adoção deseja adotar crianças de tenra idade. Esse quadro fez com que o CNJ passasse a estimular os Tribunais de Justiça a se empenharem em conseguir inserção familiar para as crianças que são, em geral, preteridas, identificadas com as seguintes características: tendo mais de 2 anos, pertencentes a grupos de irmãos, sendo de etnia negra ou identificadas com alguma deficiência.

Estudos sobre a adoção tardia indicam que os principais obstáculos que dificultam a adoção das crianças com mais de dois anos estão relacionados à cultura da adoção no Brasil, na qual o casal demarca seu desejo de adotar um bebê, ou seja, uma criança com poucos meses de idade, no intuito de substituir, 
por meio da adoção, a gravidez que não ocorreu, fato que dificulta a concretização de adoções de crianças com idade superior a 2 anos (Denby, Alford, \& Ayala, 2011; Fonseca, 2006; Santos, Raspantini, Silva, \& Escrivão, 2003). Além dos aspectos mencionados, há ainda a crença de que se deve buscar a adoção de crianças pequenas, porque é mais fácil educá-las (Mariano \& Rossetti-Ferreira, 2008; Santos et al., 2003).

Outro elemento considerado marcante e desafiador no contexto da adoção tardia é a possibilidade de que a criança tenha um comportamento hostil endereçado aos pais adotivos. Segundo Vargas (1998), esse comportamento está relacionado ao medo de um novo abandono. A criança pode testar e hostilizar os pais para se proteger de uma nova frustração, afinal a possibilidade de que ocorra nova rejeição é algo concreto, conforme apontam alguns estudos sobre a temática (Levy, Pinho, \& Faria, 2009; Moraes \& Faleiros, 2015).

Pesquisas que focam os processos de construção de maternidade, paternidade e filiação no contexto da adoção tardia demonstram, contudo, que, apesar dos desafios, a convivência e interação familiar propicia, em muitos casos, que se construa o sentimento de pertencimento familiar (Dias, Silva, \& Fonseca, 2008; Guimarães, 2010; Moraes \& Faleiros, 2015). Como afirma Vargas (1998, p. 153), seja na filiação adotiva ou biológica, "As chances de sucesso ou fracasso das relações que se estabelecem dependem da capacidade de suporte, de entrega, de trocas afetivas profundas e verdadeiras entre os protagonistas".

Assim, deve-se considerar que, além da reconstrução simbólica da questão genealógica, para que a criança se sinta integrada à nova família, é essencial que se instale uma reciprocidade nas relações construídas ao longo da interação. Espera-se que um vínculo seja gradativamente construído e que a criança seja inserida não só no cotidiano familiar, mas na história de sua família, podendo, portanto, construir o sentimento de pertencimento familiar (Levy et al., 2009).

Este estudo utilizou como fundamentação a teoria bioecológica, que considera o desenvolvimento humano como um processo de interação recíproca entre a pessoa em desenvolvimento e o contexto no qual está inserida (Bronfenbrenner, 2005). Essa teoria tem fundamentado estudos sobre a temática da adoção (Huber \& Siqueira, 2010; Merçon-Vargas, Rosa \& Dell'Aglio, 2011) e, considerando que o foco desta pesquisa é compreender a perspectiva da criança sobre seu processo de integração à nova família, a teoria bioecológica contribui para a compreensão desse fenômeno, visto que articula o desenvolvimento humano às interações que se tornam significativas e promotoras deste. Essas interações são denominadas por Bronfenbrenner (2005) como processos proximais e têm como característica serem contínuas, recíprocas e cada vez mais complexas. O autor, 
portanto, ressalta a importância da bidirecionalidade da interação na construção de relações significativas entre a pessoa em desenvolvimento e outras pessoas presentes no microssistema (Bronfenbrenner \& Morris, 2006); no caso deste estudo, o foco é o microssistema familiar.

Assim, os processos proximais são considerados como a força motriz do desenvolvimento humano por propiciarem à pessoa em desenvolvimento vivências relacionada à importância da presença de uma figura estável, que estimule a relação ao longo do tempo de forma contínua e recíproca (Diniz \& Koller, 2010). Esse conceito tem correspondência com a trajetória da consolidação dos laços afetivos conforme descrevem Cavalcante e Magalhães (2012, p. 86). Estes consideram que, apesar de alguns desafios que se apresentam aos pais e aos filhos, a adoção tardia pode oferecer à criança a oportunidade de investir na construção de relacionamentos sociais estáveis e vínculos afetivos duradouros, "em um novo e definitivo ambiente familiar", o que se acredita que pode ser vivenciado a partir das interações significativas propiciadas pelos processos proximais.

A partir desses apontamentos, este trabalho buscou conhecer a perspectiva da criança sobre o processo de tornar-se filho/filha de seus novos pais, num contexto de adoção tardia.

Considera-se que focar a criança como protagonista do processo adotivo, buscando estimular a elaboração de sua própria narrativa a respeito de sua história, favorece a construção e avaliação de metodologias de pesquisa apropriadas à investigação qualitativa com crianças. Compreender a perspectiva da criança pode ainda contribuir para subsidiar a reflexão sobre os desafios da adoção tardia, auxiliando, assim, a elaboração de estratégias de apoio às crianças e famílias que vivem esse processo. Acrescenta-se ainda que a obtenção de conhecimento sobre o processo de filiação na adoção tardia pode fundamentar a construção de argumentos que auxiliem os postulantes à adoção a compreender os pontos recompensadores da adoção de uma criança com idade superior ao perfil clássico, favorecendo a inserção em famílias substitutas das crianças que usualmente ficam excluídas.

\section{MÉTODO}

Trata-se de um estudo realizado sob a perspectiva da pesquisa qualitativa e optou-se pelo estudo de caso como estratégia metodológica. Considerou-se que o estudo de caso permitiria um contato mais prolongado e lúdico para estabelecimento de um vínculo de confiança com a criança participante (Yin, 2001), possibilitando uma proximidade maior com o campo de estudo e 
aprofundamento do tema, com o uso de diferentes recursos de coleta de dados (Coutinho \& Chaves, 2002).

\subsection{Participantes}

A pesquisa contou com a participação de uma família de classe média, que realizou uma adoção tardia ainda em processo de legalização; os laços entre a família e a criança ainda estavam sendo construídos. Constituíam a família: Helena (47 anos), casada havia 19 anos com João Augusto (50 anos), os dois tinham uma filha biológica (Beatriz, 17 anos) e, na ocasião da pesquisa, estavam com a guarda provisória de Liz (7 anos), com fins de adoção, havia 8 meses. Todos os membros da família, inclusive a criança, eram da mesma etnia. Ambos os pais trabalhavam, e as filhas frequentavam regularmente a escola. No que diz respeito à história pregressa da criança, a mãe informou que sabia pouco. Relatou que a criança foi acolhida por negligência materna e que permaneceu na instituição de acolhimento por aproximadamente um ano. A família atendia aos critérios de inclusão para o estudo que indicava que a criança a ser entrevistada deveria ter entre 6 e 12 anos, e a família deveria ter iniciado o processo adotivo há, no máximo, um ano.

\subsection{Procedimentos éticos}

Este estudo seguiu as recomendações éticas para a realização de pesquisas com seres humanos, de acordo com as orientações da Resolução n. ${ }^{0}$ 466/2012 do Conselho Nacional de Saúde, e foi aprovada pelo Comitê de Ética e Pesquisa da Universidade Federal do Espírito Santo (UFES), sob o número 1.579.323. Tanto a mãe quanto a criança consentiram em participar da pesquisa e assinaram os termos de consentimento e assentimento livre e esclarecido. Destaca-se que os nomes dos participantes e das pessoas mencionadas no estudo foram modificados para preservar o anonimato.

\subsection{Instrumentos}

O emprego da teoria bioecológica como matriz para discussão e interpretação dos dados norteou a definição dos instrumentos, uma vez que Bronfenbrenner pontuou a importância do pesquisador em se esmerar para compreender a visão do participante sobre o fenômeno investigado (Rosa \& Tudge, 2013). Assim, para a entrevista com a mãe, utilizou-se de um roteiro de entrevista semiestruturada, contendo questões relacionadas à motivação para adoção, expectativas em 
relação à adoção e adaptação da criança à nova situação. E, com a criança, foram realizadas três entrevistas orientadas por roteiros semiestruturados. Na primeira, o roteiro continha questôes que buscaram investigar como foi, para a criança, a chegada na família adotiva e seus sentimentos no que tange à filiação, nesse novo contexto de vida. Na segunda entrevista, foram apresentadas questôes sobre a percepção da criança a respeito de sua inserção social na comunidade e na escola, e sobre a participação dos familiares nas atividades realizadas nesses ambientes. $\mathrm{Na}$ terceira entrevista, foi usado um roteiro com perguntas relacionadas à convivência familiar e sentimentos de pertencimento.

Outro recurso foi o livro bibliográfico, que objetivou proporcionar à criança um momento lúdico a partir do qual ela poderia ilustrar momentos significativos vividos junto à nova família, conforme proposto por Guimarães (2010). A criança foi convidada a construir, por meio de desenhos, sua história na nova família e, durante e após sua realização, foram obtidos relatos da criança sobre as ilustrações. Buscou-se, com esse recurso, estimular a criança a relatar e ilustrar sua história de vida a partir do momento em que chegou à nova família.

O genograma, definido como uma representação gráfica da família segundo Wendt e Crepaldi (2007) e que possibilita conhecer as relaçôes afetivas entre os membros da família, também foi aplicado à criança. Com esse recurso, investigou-se a compreensão da visão da criança sobre as relações e vinculações familiares. Para essa aplicação, foram confeccionados círculos de cartolina, com rostos femininos e masculinos, para que a aplicação do instrumento fosse mais lúdica.

\subsection{Procedimentos de coleta de dados}

Todos os instrumentos de coleta de dados foram aplicados individualmente e na casa da família. As entrevistas foram gravadas. O primeiro encontro para aplicação da primeira entrevista foi realizado com a mãe adotiva, buscando conhecer como se deu o processo de adoção. Nesse momento, buscou-se o primeiro contato com a criança. No segundo encontro, foi aplicada a primeira entrevista com a criança, com o objetivo de conhecer como Liz vivenciou a chegada à família adotiva e seus sentimentos no que tange à filiação. Nesse encontro, também se iniciou a confecção do livro biográfico. No terceiro encontro, ocorreu a segunda entrevista e a continuação da construção do livro biográfico. No quarto e no último encontro com Liz, aplicou-se a terceira entrevista sobre a convivência com a família. Nessa visita, foi também aplicado o genograma. Um resumo das etapas e instrumentos utilizados na coleta de dados pode ser encontrado no quadro 1. 
Quadro 1 - Instrumentos utilizados na pesquisa em cada encontro

\begin{tabular}{|c|l|l|c|}
\hline Encontros & \multicolumn{1}{|c|}{ Temas } & \multicolumn{1}{|c|}{$\begin{array}{c}\text { Instrumentos de } \\
\text { pesquisa }\end{array}$} & Tempo \\
\hline $\mathbf{1 0}$ & $\begin{array}{l}\text { Apresentação e } \\
\text { aproximação }\end{array}$ & $\begin{array}{l}\text { Entrevista } \\
\text { semiestruturada } \\
\text { com a mãe. }\end{array}$ & 1 h45min \\
\hline $\mathbf{2 0}$ & $\begin{array}{l}\text { Apresentação e } \\
\text { aproximação } \\
\text { Tema: Adoção }\end{array}$ & $\begin{array}{l}\text { Entrevista } \\
\text { semiestruturada } \\
\text { Livro biográfico }\end{array}$ & 1 h50min \\
\hline $\mathbf{3} \mathbf{0}$ & $\begin{array}{l}\text { Tema: Escola e inserção } \\
\text { comunitária }\end{array}$ & $\begin{array}{l}\text { Entrevista } \\
\text { semiestruturada } \\
\text { Livro biográfico }\end{array}$ & 1 h50min \\
\hline $\mathbf{4 0}$ & Tema: Convivência familiar & $\begin{array}{l}\text { Entrevista } \\
\text { semiestruturada } \\
\text { Genograma }\end{array}$ & 1 h50min \\
\hline
\end{tabular}

Fonte: elaborado pela pesquisadora.

\subsection{Procedimentos de análise de dados}

A entrevista com a mãe foi empregada como forma de aproximação com a família e compreensão das questões históricas e jurídicas do projeto adotivo. A análise dos dados obtidos com a criança foi realizada considerando-se as informações coletadas de cada instrumento. Os resultados se complementaram no sentido de esclarecer a narrativa da criança a respeito de sua integração e adaptação à nova família. Os dados foram analisados a partir da análise temática, como proposto por Braun e Clark (2006). Os autores detalharam os passos dessa modalidade de análise em Psicologia e têm sido indicados como referência para pesquisadores que utilizam a análise temática (Joffe, 2011).

Assim, as informações coletadas por todos os instrumentos aplicados foram transcritas e lidas em conjunto, repetidamente, buscando-se identificar significados e padrões comuns em cada conjunto de informações, tendo em vista os objetivos e o referencial teórico de análise do estudo. Os extratos dos dados obtidos com cada instrumento, identificados com características significativas, foram agrupados com base em uma codificação inicial. A seguir, após novas leituras, foram reorganizados em temas que representassem a história expressada pelos dados. 


\section{RESULTADOS E DISCUSSÃO}

Foram encontrados alguns temas centrais que permearam as narrativas, os desenhos e as brincadeiras da criança, e assumiram relevo ao longo da análise dos dados. Assim, os resultados encontrados foram organizados nos seguintes eixos temáticos:
a) percepção sobre a adoção;
b) convivência familiar;
c) interação com os objetos e símbolos significativos;
d) interação com outros microssistemas.

\subsection{Percepção sobre a adoção}

Essa categoria temática diz respeito à forma como a criança entende e se sente em relação à sua adoção. A criança se manifestou sobre esse tema por meio de palavras, desenhos e silenciamentos. Tais manifestaçôes ocorreram em todos os encontros, quando a temática da adoção emergiu direta ou indiretamente. Observou-se que a primeira reação da criança diante da participação na pesquisa foi estimulante. Ela demonstrou interesse ao saber que seria a fonte principal de investigação e fez questão de assinar seu nome no termo de assentimento. Explorou o material lúdico e mostrou-se afoita para iniciar as atividades propostas no primeiro dia. Não obstante, ao ser convidada para a montagem do livro biográfico, a criança afirmou: "Não tenho história da minha vida". Ela brincou, explorou a caixa com materiais para montagem do livro, lanchou, fez perguntas pessoais à pesquisadora e, só após todo esse momento de exploração da situação de pesquisa, ela fez o primeiro desenho.

Embora Liz tenha encontrado dificuldades para relatar a transição entre o contexto ecológico anterior e o atual, mostrou grande disponibilidade para interagir, portando-se de forma descontraída durante todas as atividades propostas. Ao apresentar pontos para reflexão sobre sua pesquisa, Guimarães (2010) enfatizou que foi observado um processo de silenciamento do passado das crianças investigadas em relação à sua vida pregressa. Tal forma de comunicação (o silenciamento) também foi percebida em Liz, que utilizou, muitas vezes, o silêncio como resposta, principalmente em assuntos relativos aos contextos anteriores nos quais ela viveu (família biológica e abrigo, ou seja, sua vida pregressa). 
Conversando com Liz sobre como ficou sabendo que viria para a nova família, respondeu: "Eu vim porque eu quis, porque aqui é legal". Assim, ela colocou a adoção como uma situação da qual ela participou ativamente, como se tivesse assumido uma posição de controle. Diferente da ponderação de Guimarães (2010, p. 148), de que "As crianças circulam de um contexto para outro, submetidas de maneira impotente às decisões dos adultos", Liz expressou uma fantasia de que ela foi ativa no processo decisório envolvendo a adoção, relatando que foi inserida naquela família porque esse era seu desejo. Tal formulação feita por Liz demonstrou um desejo ativo da criança de fazer parte dessa nova família, o que alude à ideia de que, se os pais decidiram adotá-la, a recíproca era verdadeira. Bronfenbrenner e Morris (2006) apontam a importância da reciprocidade na construção de relações significativas. Levy, Pinho e Faria (2009) também ponderam sobre esse aspecto da interação e sua relevância na construção do sentimento de pertencimento familiar. Hamad (2002, p. 22), por sua vez, articula a ideia de reciprocidade ao contexto da filiação adotiva, ao defender que a adoção é uma ação bilateral, pois "os pais não são os únicos a adotar", uma vez que, para que o processo de filiação se inicie, é necessário que a criança também adote seus pais, aspecto destacado também por Silva e Benetti (2015).

Após algum tempo brincando e desenhando, ela conseguiu falar sobre como se sentiu quando soube que seria adotada por essa família: "Me dava vontade de chorar [ênfase na palavra chorar]. Porque você fica com uma família, depois com outra família, com milhões de famílias. Porque isso não existe para mim!”. Posteriormente, desviou-se do assunto e não retornou a ele nas entrevistas seguintes. Foi a primeira vez em que Liz conseguiu colocar em palavras a informação de que ela teve uma outra família. Contudo ela não falou sobre a questão da adoção, de modo direto, em nenhum dos encontros.

Bronfenbrenner e Morris (2006) ponderam a importância da existência de uma figura estável ao longo do desenvolvimento humano e não se sabe se a genitora de Liz ou algum outro familiar da linhagem biológica representou para ela o que Bronfenbrenner e Morris (2006) chamaram de "figura estável". Mas a forma com Liz se expressou diante de sua história pregressa demonstrou que a criança não desejava se confrontar com esse passado. Tal peculiaridade também foi observada por Guimarães (2010, p. 78), que destacou ter percebido, em sua pesquisa, uma tendência a "abortar a conversação" quando o assunto reportavase às vivências anteriores ao abrigo. Liz mostrou essa tendência ainda mais forte, pois não só evitou qualquer assunto sobre sua família como também sobre qualquer situação relacionada ao abrigo. Guimarães (2010, p. 92) atribuiu tal esquiva a uma "tentativa de zerar o cronômetro da história de sua vida", como se 
a entrada na nova família representasse um marco zero, o que parece ter ocorrido também com Liz.

Em todas as entrevistas, Liz não mencionou sua história anterior à inserção na família adotiva. Contudo, no terceiro encontro, quando foi retomada a relação entre ela e a irmã, a partir do que foi delineado no genograma, foi perguntado a Liz se gostaria de ter mais irmãos, e a criança prontamente respondeu: "Mas eu tenho!”. A seguir, falou sobre as idades e os nomes dos irmãos biológicos. A criança não quis dar detalhes sobre essa questão e não respondeu quando questionada se havia visto os irmãos novamente, embora Helena tenha relatado na entrevista que sim. Foi a primeira e única vez que Liz fez alguma referência à sua história pregressa. A dificuldade de Liz em integrar aspectos pregressos de sua história com os aspectos atuais aponta para questôes que precisam ser investigadas com profundidade, para que se possa compreender a causa dessa postura de silenciamento da criança.

\subsection{Convivência familiar}

Sobre a integração à nova família, ao longo de todos os procedimentos, a criança descreveu o novo ambiente familiar e as relações, especialmente com a mãe, com atributos positivos. Em alguns momentos, inclusive ela caracterizou a mãe como sendo extremamente paciente e tolerante às "bagunças" dela. Referiu-se a Helena como "a mamãe" e fez questão de compartilhar com a mãe as atividades que desenvolveu durante a coleta de dados. Foi observada a reciprocidade no olhar, na atenção e nos sorrisos entre Liz e a mãe. Assim, a criança expressou estar construindo o sentimento de pertencimento baseado nas trocas significativas entre ela e a mãe, ou seja, dos processos proximais estabelecidos entre elas.

Um aspecto que adquiriu relevo foi que, durante a aplicação do genograma, Liz revelou que sentiu vergonha na primeira vez em que viu aquela que seria sua nova mãe, embora não tenha conseguido descrever tal sentimento. Contou impaciente: "Eu já te falei, quando minha mãe me conheceu, eu ficava com vergonha”, e não quis falar mais sobre o assunto. Essa descrição representou a segunda vez, durante a pesquisa, na qual Liz tangenciou em sua narrativa o fato de que aquela mãe (Helena) não foi sempre sua mãe. Tal reconhecimento parece ter gerado sofrimento para a criança, e ela não retornou a ele em outro momento.

Também foi observado que, em cem por cento das vezes em que a criança se referiu à sua família, ela estava falando da nova família. Em nenhum dos encontros e relatos da entrevista, a criança se referiu à "minha nova família". Semelhante ao que ocorria em relação à mãe adotiva, Liz nomeava "minha família", como se 
fosse um fato consolidado para ela que essa família atual se configurasse como "sua" família (nunca se referindo à família anterior com a qual conviveu por seis anos). Fonseca (2007, p. 30) problematiza que a vinculação por meio da adoção era vista como um "simples suporte ao modelo clássico de família", mas explica que hoje a Antropologia defende que família constituída ou ampliada a partir da adoção se estabelece como uma forma legítima de parentesco e sentimento de pertencimento. Portanto o fato de a criança falar de sua mãe e família atuais como se não tivesse havido outra mãe ou outra família demonstra um movimento de pertencimento ativo à família na qual Liz está inserida, uma vez que, diante da possibilidade de ver-se inserida em um novo grupo familiar, a criança desenvolve a expectativa de "ser reconhecida como elemento homogêneo àquele contexto", conforme pondera Levy et al. (2009, p. 68).

Merçon-Vargas, Rosa e Dell'Aglio (2011) ressaltam que, apesar dos avanços das pesquisas contemporâneas sobre a temática da adoção, permanecem ainda muitas lacunas a serem preenchidas, principalmente com relação às dinâmicas e às estratégias de interação e adaptação que podem propiciar um ambiente familiar saudável. Durante a pesquisa realizada com Liz, foi perceptível que a família e a criança buscam estratégias de interação que demonstram facilitar a construção do sentimento de filiação na criança. Bronfenbrenner e Morris (2006) ponderam que realizar algumas atividades em conjunto, de modo contínuo, fortalece as relaçôes familiares. Foi observado que a criança desenvolve muitas atividades, de forma contínua e significativa, junto à sua família, por exemplo: assiste a filmes com a irmã, recebe auxílio da mãe nos deveres de casa, vai e volta para a escola na companhia da mãe, passa todas as manhãs em casa, junto à mãe.

Figura 1 - Representação da família

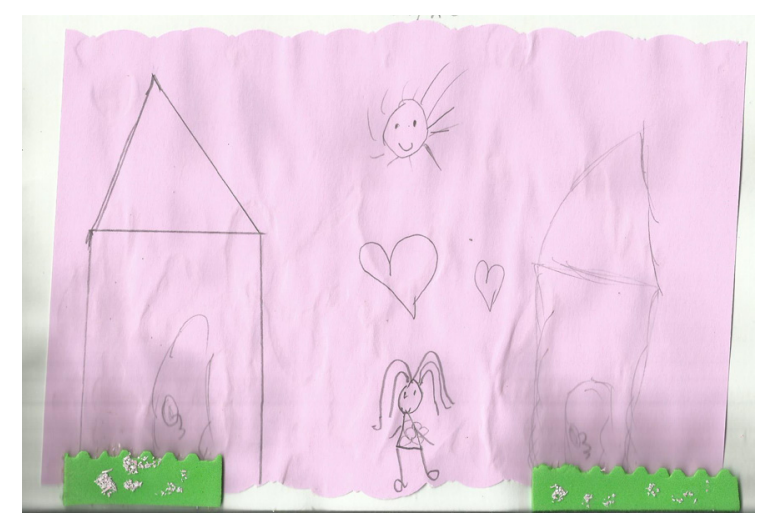

Fonte: desenho elaborado pela criança participante.

A figura 1 ilustra o segundo desenho e, ao fazê-lo para incluir no livro biográfico, Liz decidiu que faria um desenho sobre sua família e disse: "Eu vou 
falar da minha família”. No entanto, desenhou uma garotinha entre duas casas. Apontou a casa feita com linhas frágeis e falou: "Minha casa de palha"; e assinalou a outra casa como sua casa atual e avaliou que tem de bom nela: "É doces com mel". Mostrou-se agressiva e demonstrou dificuldades para discorrer sobre os desenhos detalhadamente. Assumiu uma expressão pensativa, contudo, mesmo sendo abordada em relação ao significado que essas duas casas teriam para ela, não quis dar maiores explicações sobre o desenho ou sobre sua postura.

Figura 2 - Segunda representação de família

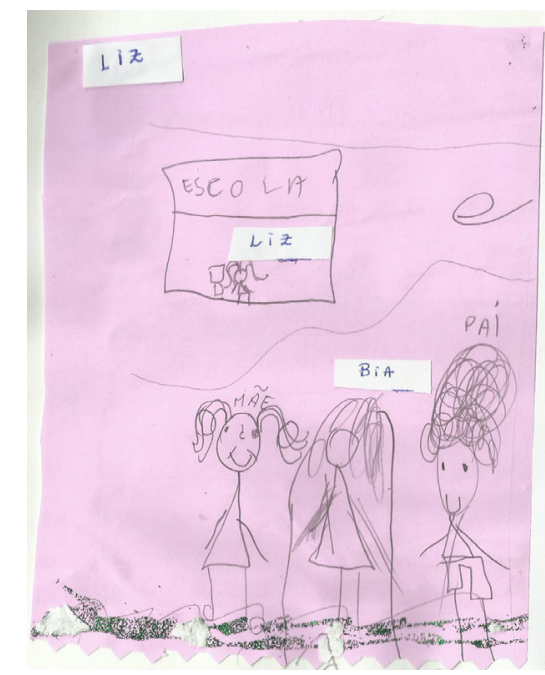

Fonte: desenho elaborado pela criança participante.

Ao fazer o terceiro desenho, também elegeu representar sua família. Desenhou sua mãe, seu pai e sua irmã, excluindo ela mesma do desenho. Uma representação de si somente foi acrescentada depois que foi questionado o motivo pelo qual ela não estava ali. Mesmo assim, ao se incluir no desenho, fez a si mesma num outro ambiente, ao qual nomeou como escola, como pode ser verificado na figura 2 .

O comportamento da criança ao falar, e ao silenciar, sobre seus desenhos indicam que o processo de integração à nova família está ocorrendo, mas ainda está em fase de construção. Partiu dela a iniciativa para desenhar sua família (nova), mas, ao se desenhar entre duas casas e ao se incluir no segundo desenho num ambiente junto, mas ao mesmo tempo separado, dos outros membros da família, Liz sinaliza que o processo de integrar as duas casas que fazem parte de sua história, e de sentir-se pertencente à nova família, ainda está em construção. Ao discorrer sobre o genograma, representou toda sua família nuclear atual. Não quis incluir mais ninguém e não cogitou fazer dois genogramas (representando sua família biológica). Ao se deparar com questóes sobre como se sente nessa 
família representada por ela, disse de maneira pontual e decidida: "Me sinto ótima na minha família”.

No que diz respeito à interação com os pais ao longo da pesquisa, nas três entrevistas, a criança interrompeu as atividades lúdicas para compartilhar com a mãe algum desenho ou algum episódio que ela considerava engraçado, ocorrido durante a interação de pesquisa. Esse comportamento da criança indica a vinculação afetiva pela mãe, pois houve a busca de proximidade e desejo de compartilhar vivências. Diniz e Koller (2010, p. 72) afirmam que, para haver o interesse mútuo dos participantes de uma interação, é necessária a "criação de um vínculo que mantenha os elementos ligados entre si, com garantia de estabilidade e reciprocidade entre as partes". Portanto foi observado que Liz constantemente buscava dividir com a mãe momentos vividos durante as entrevistas, e a mãe retribuía tais investidas com demonstraçôes afetivas.

Liz falou da mãe sempre utilizando expressões que demonstravam que ela cuidava dela e era paciente. "Mamãe comprou tudo novo para mim", "Eu adoro quando a mamãe traz o suco aqui para mim", "Eu gosto de toda a comida que a mamãe faz", "Ah, não, mamãe não vai brigar de jeito nenhum" (diante da bagunça com a purpurina). Durante a composição do genograma, ao falar de sua ligação com a mãe, representou-a como sendo muito estreita. Disse também que ela e a mãe têm conflitos, mas não quis especificar e enfatizou aspectos positivos da interação, demonstrando a eficácia dos processos proximais na relação mãe e filha. O mesmo se deu sobre sua relação com o pai, embora tenha trazido com muito menor frequência referências a ele. Na última entrevista, mencionou que o pai é quem a coloca na cama, "no colo", com visível deleite.

Não obstante a criança tenha feito menção ao pai e à irmã de forma afetuosa, majoritariamente, as falas da criança relativas aos cuidados diários, ao acompanhamento escolar e momentos de lazer foram relacionadas à mãe. Acredita-se que tal fato esteja relacionado à motivação da família para adoção, uma vez que a mãe alegou que o desejo de adotar partiu dela e que, embora toda a família tenha participado do processo decisório, o projeto adotivo foi ancorado no desejo dela de aumentar a família.

Ao discorrer sobre como nomeava os membros da família (Helena, João Augusto e Beatriz) nos primeiros dias em que chegou à família, a criança explicou que os chamava de tia, tio e colega, respectivamente, e que passou a chamá-los "de mãe, pai e irmãzinha". Não conseguiu explicar quando ocorreu a mudança nem o que fez com que ela mudasse o jeito de nomeá-los. Mostrou-se claramente aborrecida por falar nesse assunto, disse não "querer papo" e encerrou o assunto. 
Observou-se que a postura arredia da criança em relação a esse assunto está relacionada a outros momentos nos quais ela "abortou a conversação", por associar tais temas à realidade factual de que ela pertenceu anteriormente a outra família, o que também foi pontuado por Guimarães (2010) em seu estudo.

Um aspecto que merece destaque é que algumas pesquisas realizadas no contexto da adoção tardia ilustram o quanto a ameaça de devolução das crianças está presente no novo ambiente, principalmente quando os pais se sentem desafiados e testados pela criança (Levy et al.,2009; Moraes \& Faleiros, 2015). Contudo, nem na entrevista com a mãe nem nos instrumentos aplicados à criança compareceu nenhuma menção a essa questão, embora tanto a mãe quanto a filha tenham mencionado que houve momentos de tensão ao longo da interação criança-família.

No que tange à irmã, a primeira referência a Beatriz demonstrou ter um sentido competitivo: "Acho que vou fazer primeiro do que Beatriz". Já na segunda vez em que mencionou a irmã, disse que se sentia bem por dormirem juntas, no mesmo quarto. Durante a entrevista, surgiu o tema da privacidade, da apropriação que Liz faz dos objetos da casa. Nesse contexto, surgiu o assunto "Alguém mexe nas suas coisas?", e ela relatou que "Tem algumas vezes, que Bibi gosta de mexer na minha vida”. Descreveu a irmã como alguém participante de sua rotina, que inclusive a busca na escola muitas vezes. Sobre o dever de casa, contou que Beatriz "ajuda alguns dias", acrescentando que essa aproximação depende do seu estado emocional: "Ela só ajuda quando eu não estou mal-humorada”.

Figura 3 - Genograma

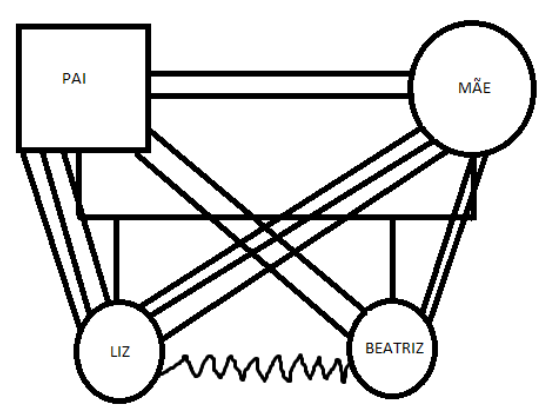

Fonte: elaborado pela criança participante.

No genograma, exposto na figura 3, Liz se posicionou no esquema familiar antes da irmã, mesmo com a explicação de que quem nasceu primeiro deveria aparecer primeiro. Explorando esse instrumento, representou sua ligação com Beatriz como conflituosa, mas disse: "Eu e Bibi briga um pouco, só que a gente se ama”. Representou a interação entre a irmã e os pais com duas linhas e chamou 
de ótima, mas frisou para a pesquisadora que tal ligação apenas deveria ter duas linhas, enquanto, ao representar sua própria relação com os pais, inseriu três linhas, o que indica relação mais estreita. Sorriu silenciosamente diante dessa comparação, de uma forma que parecia expressar consciência de que estava representando a ligação entre ela e os pais como mais próxima do que a relação existente entre os pais e Beatriz. Pereira e Lopes (2013, p. 280) afirmam que rivalidade entre irmãos difere da competição, pois, na competição, observar-se-ia a "busca por superar o irmão, circunscrita ao relacionamento a dois, enquanto que a rivalidade equivaleria à busca por superar o irmão em face de um terceiro", nesse caso, o amor dos pais. Desse modo, apesar das narrativas de Liz expressarem o estabelecimento de processos proximais com a irmã, pois a criança descreveu que realizam juntas atividades significativas e que se mantém com regularidade, Liz demonstrou a rivalidade descrita pelos autores.

\subsection{Interação com objetos e símbolos significativos}

Liz mostrou-se feliz e à vontade na casa, durante a realização de todos os procedimentos investigativos. Contou com alegria sobre a cama nova que ganhou. Mostrou também alguns brinquedos, com exaltação. Mostrou-se tranquila ao sujar o ambiente com os materiais lúdicos, sem receio de ser cerceada ou repreendida pela mãe. Durante o momento da segunda entrevista, soltou várias gargalhadas ao brincar com o banquinho da bateria de brinquedo, por quase cair dele. Repetiu muitas vezes esse gesto, mostrando-se feliz e se autorizando a se apropriar da casa como um espaço seu. Mostrou panos e outros objetos que ela pinta.

Isso mostra apropriação da casa e objetos, sinalizando o quanto a criança sente-se segura para manusear os objetos que compóem seu ambiente e o quanto se sente fazendo parte desse novo espaço que ela passara a habitar havia oito meses. Bronfenbrenner e Morris (2006) pontuaram a importância de se estudar a relação de um ser humano com objetos e símbolos significativos, pois compreendia o quanto tais estudos poderiam revelar sobre as interações. Tal aspecto é pouco pesquisado no contexto da adoção tardia e merece destaque, pois uma criança que foi institucionalizada passa muito tempo submetida a normas que coletivizam os objetos que compõem o cotidiano. Ao serem inseridas numa nova família, elas valorizam muito os objetos que simbolizam o quanto seu espaço está demarcado na nova casa, com base em atitudes dos pais como reservar uma cama, brinquedos e objetos que são de uso exclusivo da criança. Liz demonstrou, em diversos momentos, o quanto isso a deixava contente e segura 
nesse novo ambiente familiar dizendo: "Daí minha mãe comprou uma cama nova para mim. Então eu e Bibi dividimos o quarto, e eu gosto de dormir com ela". Liz demonstrou valorizar cada objeto dela e falou com alegria sobre eles. Assim, podemos analisar que os processos proximais com objetos e símbolos presentes no microssistema familiar de Liz também favorecem o desenvolvimento de seu sentimento de pertencimento e filiação na família, pois tanto chamam a atenção para o seu lugar nesse novo ambiente quanto explicitam a preocupação e o afeto dos membros da família para com ela.

\subsection{Interação com outros microssistemas}

A teoria bioecológica destaca a importância do microssistema, ao afirmar que esse contexto se configura como palco da expressão dos processos proximais (Bronfenbrenner \& Morris, 2006), pois nele ocorrem as atividades face a face experienciadas pela pessoa em desenvolvimento. No que diz respeito ao ambiente escolar, ressalta-se que Liz continuou na mesma escola que estudava durante o período da institucionalização. Assim, durante a pesquisa, tornou-se evidente o quanto a escola representa um importante microssistema à Liz, visto que é o único ambiente que se manteve estável durante todas as transições que a criança vivenciou desde que foi retirada do lar materno e até o momento em que foi inserida numa nova família.

A interação da escola com a família, o que compõe, para a teoria bioecológica, o mesossistema, apareceu no relato de Liz apenas quando ela mencionou que a irmã a busca ao fim das aulas e a ajuda nas tarefas escolares. Além disso, a criança inseriu a escola em seu desenho e falou positivamente sobre suas relações com as colegas.

Sobre a relação com a família extensa, a criança mencionou, na segunda entrevista, que passearia na casa da família em outro Município, sem entrar em detalhes sobre o assunto. Na terceira entrevista, falou novamente sobre esse espaço e sobre os primos que encontrava quando ia a tal município. Ao discorrer sobre o primeiro contato com eles, a criança considerou que os primos ficaram com vergonha e que ela também ficou, mas falou utilizando adjetivos positivos sobre sua interação com esses familiares. Diante da questão que abordava a forma como foi recebida pela família, respondeu: "Eu gosto de brincar com meus primos Flávia, Valentina, Pedro e João.”

Liz discorreu sobre a família extensa, demonstrando naturalidade. Expressou, com alegria, que circula entre sua casa e a casa dos avós, e se sente bem nesse ambiente, embora ela diferencie claramente a família extensa de sua família nuclear. Do ponto de vista jurídico, a adoção de uma criança é iniciada e 
concretizada pelos postulantes à adoção (Dias \& Lima Neta, 2007). Contudo Hamad (2002) enfatiza que cabe também aos avós inscrever o novo membro da família na cadeia de gerações. Assim, o papel da família extensa na adaptação da criança ao novo lar é relevante (Dias, 2006), pois o fato de a família extensa receber afetivamente esse novo membro, designando a ele um lugar na genealogia, constitui-se como um elemento que contribui com a construção do sentimento de pertencimento da criança a esse novo contexto ecológico representado pela família adotiva. No caso de Liz, ao expressar que se sentia bem na casa dos avós e dos primos, infere-se que há, nesse contexto, um acolhimento da criança, o que contribui para o desenvolvimento de seu sentimento de pertença à nova família.

\section{Considerações finais}

Embora seja um ponto pacificado entre a comunidade científica a existência de múltiplos fatores que se constituem como motriz do desejo de adotar, não há como negar que, independentemente do que fundamenta a motivação de um casal ou de um adulto, o ato de ensejar uma adoção é resultado de uma escolha. Contudo o sistema de Justiça funciona sob alicerces que privilegiam a lógica do adulto nos processos judiciais que envolvem a inserção da criança em uma nova família, de forma que a escolha pela adoção é unilateral (apenas o adulto participa desse processo decisório). Em contraposição a esse funcionamento, neste trabalho, optou-se por ouvir o que a criança tem a dizer e compreender, a partir de sua perspectiva, a inserção da criança adotada tardiamente numa nova família.

As intervenções realizadas com Liz evidenciam o quanto a criança afirmava e reafirmava sua alegria de estar na nova família, o quanto ela se sentia pertencendo a esse novo contexto, mas evidenciaram também que seria importante favorecer à criança uma elaboração do que ela vivenciou antes e durante o processo da adoção. Como a pesquisa aqui descrita não objetivou conhecer como foi a vivência da criança na instituição de acolhimento, não é possível afirmar se a criança foi efetivamente preparada ou não para ser inserida na nova família. Contudo as intervenções realizadas durante a coleta de dados revelaram que Liz mostrou dificuldades para expressar seus sentimentos e percepções em relação ao rompimento com os vínculos estabelecidos antes da adoção e sobre as mudanças ocorridas no momento em que foi decidido que ela seria inserida num novo contexto familiar. No entanto, a partir da brincadeira, da risada, do silêncio, da possibilidade de falar e ser ouvida, Liz conseguiu expressar que também adotou seus novos pais e que deseja continuar edificando a relação que possibilita para ela sentir-se parte daquela família, daquela casa. Verifica-se que a criança se 
posicionou ativamente nos novos contextos que faziam parte de sua vida a partir da adoção e que era também protagonista na vinculação com seus pais e com sua irmã, evidenciando que o processo de integração familiar teve seu início.

Como limites deste estudo, pode-se apontar o fato de que o aspecto tempo não foi diretamente analisado. Seria importante o acompanhamento longitudinal dessa criança e de outras crianças que vivenciam a adoção tardia, proporcionando maior conhecimento das mudanças e permanências presentes em seu desenvolvimento, ao longo das interações na nova família, além da observação mais detalhada dos aspectos que facilitam o fortalecimento dos vínculos e dos desafios enfrentados por todos os membros nessa construção.

Considera-se, contudo, que, ao buscar conhecer melhor o ponto de vista da criança, este estudo contribuiu para ampliar o conhecimento a respeito da vivência da criança ao ser inserida numa nova família. Considera-se que o estudo também alerta para a necessidade da elaboração de intervenções que possibilitem à criança integrar à sua nova história as vivências do passado que também a constituem, apoiando também as famílias nesse processo. Além disso, pôde-se observar a importância do brincar como procedimento metodológico ao longo da aplicação dos instrumentos de coleta de dados e o quanto a criança buscou formas lúdicas de interação durante todos os momentos da pesquisa, a partir da qual ela conseguiu trazer à tona percepções repletas de significado e profundidade para o tema investigado. Tal constatação reafirma a relevância da interação lúdica em pesquisas com crianças. 


\section{REFERÊNCIAS}

Braun, V. \& Clarke, V. (2006). Using thematic analysis in Psychology. Qualitative Research in Psychology, 3(2), 77-101.

Bronfenbrenner, U. (2005). Making human beings human: biological perspectives on human development. Thousands Oaks: Sage.

Bronfenbrenner, U., \& Morris, P. A. (2006). The biecological model of human development. In W. Damon, W., \& R. M. Lerner, Handbook of child psychology: theorical models of human development. (pp. 793-828). New York: John Wiley $\&$ Sons.

Cavalcante, L. I. C., \& Magalhães, C. M. C. (2012). Relações de apego no contexto da institucionalização na infância e da adoção tardia. Psicologia Argumento, 30(68), 75-85.

Corsaro, W. (2009). Reprodução interpretativa e cultura de pares. In F. Muller, \& A. M. A. Carvalho. Teoria e prática na pesquisa com crianças: diálogos com Willian Corsaro. (pp. 31-50). São Paulo: Cortez.

Coutinho, C. P., \& Chaves, J. H. (2002). O estudo de caso na investigação em tecnologia educativa em Portugal. Revista Portuguesa de Educação, 15(1), 221243.

Denby, R., Alford, K. A., \& Ayala, J. (2011). The journey to adopt a child who has special needs: parent's perspectives. Children and Youth Services Review, 33, 1543-1554.

Dias, M. C. S. B. (2006). A importância da família extensa na adoção. In S. S. M. Schettini \& L. Schettinni Filho. Adoção: os vários lados dessa história. (pp. 173-193). Recife: Bagaço.

Dias, M. C. S. B., \& Lima Neta, M. I. F. (2007). A adoção na perspectiva dos avós adotivos. In T. Féres-Carneiro. Família e casal: saúde, trabalho e modos de vinculação. (pp. 323-339). São Paulo: Casa do Psicólogo.

Dias, M. C. S. B., Silva, R. V. B., \& Fonseca, C. M. S. (2008). A adoção de crianças maiores na perspectiva dos pais adotivos. Contextos Clínicos, 1(1), 2835 .

Diniz, E., \& Koller, S. H. (2010). O afeto como um processo de desenvolvimento ecológico. Educar, 36, 65-76. 
Fariello, L. (2016, 30 março). Casais quebram barreiras com adoção tardia e de grupos de irmãos. Agência CNJ de Notícias. Recuperado a partir de https:// www.cnj.jus.br/casais-quebram-barreiras-com-adocao-tardia-e-de-grupos-deirmaos/

Fonseca, C. (2006). Da circulação de crianças à adoção internacional: questôes de pertencimento e posse. Cadernos Pagu, 26, 11-43.

Fonseca, C. (2007). De família, reprodução e parentesco: algumas considerações. Cadernos Pagu, 29, 9-35.

Guimarães, L. A. (2010). Conversando com crianças sobre adoção. São Paulo: Casa do Psicólogo.

Hamad, N. (2002). A criança adotiva e suas famílias. Rio de Janeiro: Companhia de Freud.

Huber, M. Z., \& Siqueira, A. C. (2010). Pais por adoção: a adoção na perspectiva dos casais em fila de espera. Psicologia: Teoria e Prática, 12(2), 200-216.

Joffe, H. (2011). Thematic analysis. In D. Harper, \& A. R. Thompson (Orgs.), Qualitative methods in mental health and psychotherapy: a guide for students and practitioners. (pp. 209-224). Chichester: Wiley.

Levy, L. (2009). Adoção internacional: filiação e processo de luto. In T. FéresCarneiro (Org.), Casal e família: permanências e rupturas. (pp. 60-70). São Paulo: Casa do Psicólogo.

Levy, L., Pinho, P. G. R., \& Faria, M. M. (2009). Família é muito sofrimento: um estudo de caso de "devolução" de crianças. Psico, 40(1), 58-63.

Mariano, F. N., \& Rossetti-Ferreira, C. M. (2008). Que perfil da família biológica e adotante e da criança adotada revelam os processos judiciais? Psicologia: Reflexão e Crítica, 21(1), 11-19.

Merçon-Vargas, E. A., Rosa, E. M., \& Dell'Aglio, D. D. (2011). Adoção nacional e internacional: processos proximais no período de convivência. Salud \& Sociedad, 2(3), 268-283.

Misca, G., \& Smith, J. (2014). Mothers, fathers, families and child development. In A. Abela, \& J. Walker. Contemporary issues in family studies: global perspectives on partnerships, parenting and support in a changing world. (pp. 151-165). New York: John Wiley \& Sons. 
Moraes, P. J. F. S., \& Faleiros, V. P. (2015). Adoção e devolução: resgatando histórias. São Paulo: Paco.

Pereira, R. C. S., \& Lopes, C., R. R. (2013). Rivalidade fraterna: uma proposta de definição conceitual. Estudos de Psicologia, 18(2), 277-283.

Rosa, E. M., \& Tudge, J. (2013). J. Urie Bronfenbrenner's theory of human development: it's evolution form ecology to bioecology. Jornal of Family: Theory \& Rewiews, 5, 243-258.

Rosseti-Ferreira, M. C. (2010). Prefácio. In L. A. Guimarães, Conversando com crianças sobre adoção. (pp. 19-21). São Paulo: Casa do Psicólogo.

Santos, M. A., Raspantini, R. L., Silva, L. A. M., \& Escrivão, M. V. (2003). Dos laços de sangue aos laços de ternura: o processo de construção da parentalidade nos pais adotivos. Psic: Revista da Vetor Editora, 4(1), 14-21.

Schweiger, W. K., \& O’Brien, M. (2005). Special needs adoption: an ecological systems approach. Family Relations, 54(4), 512-522.

Silva, C. L., \& Benetti, S. P. C. (2015). Older child adoption: a study of the affiliation process. Estudos de Psicologia, 32(1), 121-127.

Silva, J. A. (2010). Adoção de crianças maiores: percepções e vivências dos adotados. Psicologia em Revista, 16(2), 434-436.

Vargas, M. M. (1998). Adoção tardia: da familia sonhada à família possivel. Rio de Janeiro: Casa do Psicólogo.

Wendt, N. C., \& Crepaldi, M. A. (2007). A utilização do genograma como instrumento de coleta de dados na pesquisa qualitativa. Psicologia: Reflexão e Critica, 21(2), 302-310.

Yin, R. K. (2001). Estudo de caso: planejamento e métodos. Porto Alegre: Bookman. 